\title{
O discurso da Literatura Sul-riograndense na pesquisa e nas formas de disciplinarização do saber produzido localmente
}

Daiane Siveris ${ }^{\circledR}$

\section{Introdução}

A segunda metade do século $X X$ é marcada pela leitura e releitura de obras literárias que revelam a "cor local" e as nuances do regionalismo, em diferentes partes do Brasil. A década de 70, em especial, é marcada pelo processo de institucionalização do "saber sobre" a literatura regionalista, especialmente no tocante ao Rio Grande do Sul.

O presente artigo destaca a importância da pesquisa e da disciplinarização do "saber local", via Literatura Sul-rio-grandense. Ainda que a maior precursora desse processo tenha sido a PUC-RS, na qual também ocorre a institucionalização de disciplinas voltadas ao regionalismo sul-rio-grandense, em 1971; o presente levantamento histórico pode apontar a UFRGS como instituição pública federal com papel fundador, pois é nessa universidade que, em 1973, são criados os programas de pós-graduação de várias áreas do conhecimento.

Destacaremos, nesse trabalho, especialmente, algumas das idéias veiculadas na obra Simões Lopes Neto: regionalismo e literatura, resultado da tese de Flávio Loureiro Chaves, cuja primeira versão data de 1980, tendo sido apresentada em primeira instância à Faculdade de Filosofia, Letras e Ciências Humanas da Universidade de São Paulo. O professor orientador desse trabalho foi o Prof. Dr. José Aderaldo Castello.

Flávio Loureiro Chaves tinha por objetivo a obtenção do grau de doutor, mas com isso elevou para um outro estatuto a produção literária gaúcha. A sua proposta foi de realizar uma análise detalhada de Contos Gauchescos, de João Simões Lopes Neto, relatando, nas entrelinhas, costumes do Rio Grande do Sul, bem como estabelecendo relações de semelhança e de diferença quanto ao regional propriamente dito e ao universal.

\footnotetext{
(c) Aluna de Graduação em Letras da UFSM, participante do projeto "A Literatura Regionalista Gaúcha na História das Idéias Lingüísticas", que recebeu apoio da FAPERGS/RS, pela modalidade ARD, em 2006-2007.
} 


\section{Do universal, do nacional e do local}

No contexto nacional, temos uma referência importante na ideologia machadiana, que se firma na busca de uma literatura independente, mas cujas características não estejam totalmente voltadas ao indianismo. Sendo assim, o regionalismo surge fundamentado nessa ideologia, apontando para a possibilidade de o texto literário valorizar os modelos locais. José de Alencar também é um nome que deve ser destacado, pois procurou incansavelmente a criação de um herói nacional na imagem do índio Guarani; e depois buscou a criação de um herói local para diferentes regiões do Brasil, na imagem do Sertanejo e do próprio Gaúcho. Ele foi e é muito criticado, mas tem o mérito de ser o precursor na produção de uma literatura nacional visionária, capaz de considerar em seus meandros a importância do regionalismo (PETRI, 2004).

Em suma, a influência da obra $\mathbf{O}$ Gaúcho, de José de Alencar, nada mudou após as críticas que recebeu. Mesmo retratando o gaúcho distorcidamente quanto à linguagem, às crenças e aos costumes, não podemos negar que foi uma das primeiras obras a tratar do regional, embora voltado ao universal, uma vez que ele buscava um herói capaz de representar um povo diante do mundo. Foi também nessa mesma obra que Simões Lopes Neto buscou elementos (lendas e falares), para desenvolver Contos Gauchescos, na qual procurou abordar não apenas um linguajar sul-rio-grandense, mas uma linguagem mais regionalista, mais tarde denominada como gauchesca.

Críticos, como José Veríssimo, Lúcia Miguel-Pereira e Antônio Cândido, voltam-se ao objeto das obras, o sertão e o sertanejo, baseado nos modelos europeus. O fato que persiste é de que o regionalismo sempre existirá, seja baseado em aspectos locais, seja em estrangeiros, através dos quais se poderá chegar ao universal. Muito embora, na tese de Chaves (1982), deparamos-nos com a dificuldade que ele aponta em, utilizando elementos locais, chegar ao universal, pois a utilização do falar, das crenças, dos costumes, tudo está voltado especificamente ao regional. E o universal utiliza elementos que valorizam não só o local, mas também o coletivo; sendo que este pode designar o conhecimento que grande parte do povo, senão a maioria, possui, e que está assimilado, instituído histórica e simbolicamente. 
A tese de Chaves, então, revela um lugar de fundação para o trabalho de Simões Lopes Neto, pois antes dele não há possibilidade de atingir, pela literatura, o universal, ao destacar valores locais, uma vez que há uma contradição interna entre realidade e sonho, a qual se resolverá nas obras simonianas. Ou seja, a obra simoniana não revela o novo, ela compila o que já existe, jogando com a cor local. Em Simões, é recorrente a descrição de elementos presentes nas obras de José de Alencar e nos elementos sugeridos pelo Partenon Literário, cujas atividades, segundo Regina Zilberman (1992, p.13), "expressavam preocupações com a abolição da escravatura ou a educação noturna para adultos". Porém, esses elementos se apresentam, na obra simoniana, com uma linguagem diversamente elaborada, destacando o regionalismo e apontando para a universalidade.

\section{A relevância do trabalho de pesquisa para a institucionalização do saber}

É interessante observar o estudo da obra de Simões Lopes Neto por Flávio Loureiro Chaves, realizado na década de 70, porque ele revela o espaço geográfico, os costumes e os hábitos regionais do estado sulino, através da análise da linguagem coloquial presente na obra. O tipo do gaúcho se concretiza com a criação do vaqueano Blau Nunes, pois através dele serão retratados aspectos locais que caracterizam o homem sulino. Surge, assim, a imagem da raça gaúcha, perfeita, viril, auto-suficiente, que ainda não se alterou pelo progresso da sociedade.

Uma tese de doutorado sobre essa temática faz deslanchar o processo de institucionalização de um saber que, até então, estava incipiente nos cursos de graduação e de pós-graduação, fazendo parte, apenas de um saber próprio do senso comum, revelador de um bairrismo muito próprio ao gaúcho.

Por tudo isso se justifica a opção de destacarmos a tese de Chaves (1982), que contribui essencialmente, em nosso entender, para a consolidação do processo de institucionalização das disciplinas voltadas ao regionalismo no Rio Grande do Sul. Isso porque, se considerarmos os tipos, os costumes, os hábitos, 0 espaço e a descrição da "cor local", podemos afirmar que as obras alencarianas já estão impregnadas de regionalismo; no entanto, esse regionalismo funde-se com o nacionalismo, pressupondo um "americanismo", que Alencar defende como tipo gaúcho, "um vulto 
ideal derivado da idealização da paisagem" (CHAVES, 1982, p.26). Retrata-o como machista e o apresenta estreitamente ligado ao cavalo, características que também estarão presentes nas obras simonianas. Zilberman (1992) aponta que

Simões Lopes Neto dá dimensão artística ao tipo regional enquanto um modelo propiciado pelo solo rio-grandense e solidário a ele; mas revela que este mundo está terminado por razões verificáveis na história contemporânea do Estado.

A imagem do gaúcho de Simões, então, perpetua-se no discurso literário, buscando um outro espaço para a realização do mito. Se retrocedermos no tempo, via discurso da história, encontraremos um gaúcho que nem sempre foi designado de forma heróica. Na época colonial, o homem que lida no campo é o guasca, o mesmo que, nos séculos XVIII e XIX, chama-se gaudério, representando os ladrões de gado, aventureiros paulistas. Somente no final do século XIX surge o termo gaúcho, representando o homem guerreiro e peão, o qual é, ao mesmo tempo, campeador e combatente na luta contra 0 inimigo. Ainda nesse período, no monarca das coxilhas, fundem-se o mito e a realidade. $\mathrm{O}$ que, mais tarde, passará a designar o homem que nasceu e/ou que vive no Rio Grande do Sul.

Para Chaves (1982), na linguagem de Simões Lopes Neto, o cenário regional constitui o mito da natureza e da "epifania" do mundo natural,

gerado na impugnação do presente histórico que se degradou com a violência e dominação(...) A expressão simoniana assinala um momento decisivo na tradição regionalista gaúcha e brasileira (...), porque (...) impõe esta visão do mundo que exige o contraste, o paradoxo, o símbolo e a metáfora como seus fundamentos e leva-nos à fronteira da linguagem.(p.233)

Contos Gauchescos, enfim, confronta o homem e o mundo da natureza, ao nomear uma região, seus tipos característicos, sua tradição e seu folclore. A memória é individual e coletiva. A imaginação confronta o mundo da realidade e o mundo da ficção. $O$ mundo imaginário de Simões Lopes Neto nasce, assim, na conquista da linguagem.

A pesquisa científica que toma esse discurso produzido por Simões Lopes Neto contribui para a afirmação dessa literatura local, 
fundando um lugar institucional para esse saber, revelando a importância da disciplinarização da Literatura Sul-rio-grandense.

\section{A Literatura Sul-rio-grandense na História das Idéias}

A obra O Corsário, de Caldre e Fião, é o primeiro documento que assinala a presença do gaúcho na prosa de ficção brasileira, e também o primeiro a fazer o aproveitamento da historia do Rio Grande do Sul. A partir de 1868, quando surge a Sociedade Partenon Literário, observa-se um maior culto ao folclore, à história, à linguagem, levando, assim, à valorização do regional.

Levando em conta a afirmação de Guilhermino César sobre a contribuição do Partenon Literário em relação à literatura, pode-se dizer que foi com a obra $\mathbf{O}$ Vaqueano, de Apolinário Porto Alegre, que surgiu a literatura regionalista gauchesca. Destacava-se, nas obras, a descrição dos lugares, dos folclores da região, do homem peão e herói, ocupando, dessa forma, o lugar que já fora do negro e do índio.

Chaves (1982) explicita o processo de construção da obra simoniana. Para o pesquisador, Simões Lopes Neto era um homem citadino, que viveu pouco a realidade campesina e, por isso, necessitou recorrer a diversas fontes para elaborar suas obras. $O$ Cancioneiro Guasca é uma delas. Pra escrever Contos Gauchescos, essa foi sua fonte primeira, pois reunia falares, costumes e crenças da população. Outra fonte importante é Recordações Gaúchas, de Luís Araújo Filho, na qual observa-se "o registro objetivo da paisagem e dos costumes,(...) o linguajar dos campeiros" (CHAVES,1982, p.68) e o folclore. Na construção d'A Salamanca do Jarau, Simões Lopes Neto toma emprestado não só o folclore e a tradição, mas também a lenda. Muito recorrente também nas obras de Lopes Neto e de escritores anteriores é a descrição da valentia pessoal, o domínio sobre o reino animal e a integração à natureza.

Chaves (1982) revela ainda que, nas obras de Simões Lopes Neto, existem certas inovações na construção discursiva. Os títulos não estão diretamente ligados à narrativa, muito pelo contrário, constituem-se numa uma relação oposta, como, por exemplo, no conto $O$ Negro Bonifácio, no qual o negro de que fala o título não é o protagonista, sendo na verdade uma mulher, a personagem Tudinha. A oposição homem/mulher, masculino/feminino, também 
está presente nas obras simonianas. A mulher é vista, ora como bicho imundo, ora como bicho caborteiro. A violência devastadora é tema recorrente de Simões Lopes Neto, sendo que o homem ora é designado bicho-homem, ora como bicho-mau.

Em relação a Contos Gauchescos, pode-se afirmar que a viagem de Blau Nunes é a certeza de que se manterá uma seqüência lógica no narrar dos fatos. Apesar de citar e inserir acontecimentos históricos, Simões Lopes Neto não os problematiza, apenas transcreve fatos de uma determinada tradição. $O$ assunto de Contos Gauchescos é a memória, enquanto recordação que revela um passado marcado pela presença do gaúcho e do gaudério, os quais não permitem dupla interpretação, conforme explicita Chaves (1982, p. 133):

Gaudério é um tipo social nos primórdios da antiga Província de São Pedro, durante o período (...) do aventureiro que desertava das tropas regulares, identificando-se com a vida rude dos coureadores, contrabandistas, vagabundos e ladrões de gado.

Enquanto gaúcho é um termo

que só aparece em época relativamente recente, como substitutivo do primeiro e dotado de sentido encomiástico, mercê da ideologia patriarcal que revestiu o tipo duma aura 'heróica', escamoteando sua origem.

Os textos dos Contos Gauchescos confrontam o presente e o passado, que nada menos é que o confrontar de estancieiros e peões, caracterizando a condição histórica do homem ou recuperando a dimensão mítica do tempo passado.

Dado importante que Chaves (1982) destaca da obra simoniana é a introdução da tradição gaúcha. Como exemplo, destaca-se a carreira em cancha reta, reveladora das relações entre dominadores e dominados, patrão e empregado, constitutivas da sociedade em plena formação. Importa ressaltar que o gaúcho ideado por Simões Lopes Neto de forma alguma corresponde ao estancieiro, mas representa um tipo social caracterizado por um conjunto de valores -- coragem, lealdade, amizade e confiança -- que é atribuído aos peões, posteiros, agregados e escravos.

Chaves, ao produzir sua tese de doutorado, estudando a literatura simoniana, fornece um estatuto diferenciado à literatura 
regionalista gaúcha, fornecendo-lhe o status de objeto de estudo relevante para a academia, e contribuindo com a institucionalização dessa literatura como disciplina, em cursos de graduação e de pósgraduação no Rio Grande do Sul.

Com a criação dos programas de pós-graduação da PUCRS e da UFRGS, no início dos anos 70, tem-se como centro das atenções os autores gaúchos. Lembrando-se que, assim que surgiram esses cursos, um dos primeiros mestrandos foi Chaves. Destaca-se, ainda, em especial, o nome de Flávio Loureiro Chaves, porque os trabalhos defendidos por ele eram voltados à literatura Sul-rio-grandense. $\mathrm{Na}$ verdade, ele trabalhou Érico Veríssimo, no mestrado, e com Simões Lopes Neto, no doutorado.

Tendo em vista a proximidade da defesa do trabalho de Chaves (1982), entre outros de seus contemporâneos, com a criação desses cursos, cabe ressaltar que era uma época em que a institucionalização das disciplinas estava voltada a temas referentes não só ao gauchesco, mas também ao sul-rio-grandense. Um saber regional, ficcional e cultural que passou a ter o estatuto de disciplina e que constitui toda a história dos Cursos de Letras das Universidades Federais no Rio Grande do Sul.

\section{Referências bibliográficas}

CHAVES, Flavio Loureiro. (1982) Simões Lopes Neto: regionalismo e literatura. Porto Alegre, Mercado Aberto.

PETRI, Verli (2004). Imaginário sobre o gaúcho no discurso literário: da representação do mito em Contos Gauchescos, de João Simões Lopes Neto, à desmitificação em Porteira Fechada, de Cyro Martins. Porto Alegre: UFRGS, Instituto de Letras. Tese de Doutorado.

ZILBERMMAN, Regina. (1992) A literatura no Rio Grande do Sul. $3^{\mathrm{a}}$ ed. Porto Alegre, Mercado Aberto. 